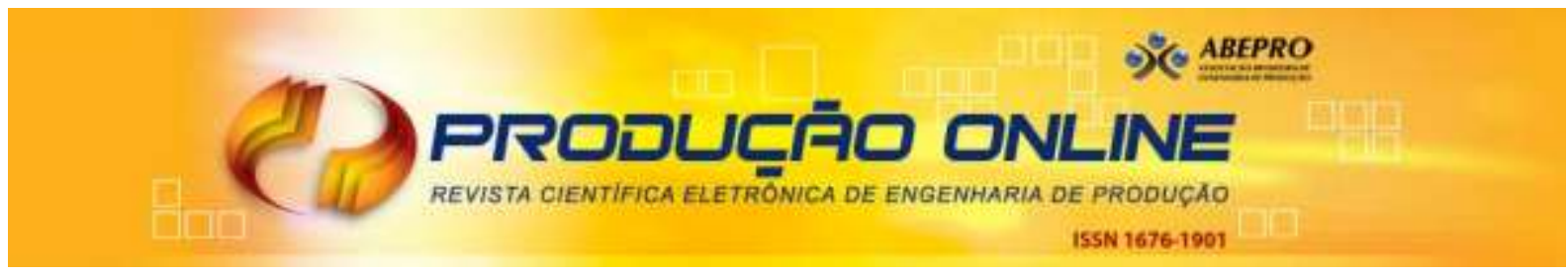

\title{
OTIMIZAÇÃO DO PROCESSO DE FUNDIÇÃO SOB PRESSÃO APLICANDO O MÉTODO DE TAGUCHI
}

\section{DIE CASTING PROCESS OTIMIZATION USING TAGUCHI METHOD}

\author{
Denilson José Viana* E-mail: djviana@gmail.com \\ Antônio Faria Neto** E-mail: antfarianeto@gmail.com \\ *Universidade de Taubaté - UNITAU, Taubaté, SP \\ *Universidade Estadual Paulista - UNESP, Guaratinguetá, SP
}

\begin{abstract}
Resumo: O processo de fundição sob pressão de alumínio tem se desenvolvido significativamente nas últimas décadas, ocupando um lugar de destaque na indústria por produzir componentes de engenharia inovadora. Dentre os problemas de qualidade deste processo, o mais recorrente é a porosidade causada por vários fatores, dentre eles os parâmetros do processo que são de difícil determinação, sendo comumente selecionados por meio da abordagem de tentativa e erro. A presente dissertação buscou responder a pergunta: Como determinar a melhor configuração de parâmetros do processo de fundição sob pressão de alumínio para minimizar a porosidade nas peças produzidas? Tendo como objetivo a melhoria da qualidade de uma peça de alumínio, fundida sob pressão, por meio da redução da porosidade. A principal contribuição desta dissertação concentra-se na aplicação do método de Taguchi utilizando dados categóricos ordinais (classes de porosidades) como característica de qualidade, por meio da análise da relação sinal-ruído ponderada. Os resultados dos experimentos foram analisados a partir do efeito médio dos fatores e da análise de variância (ANOVA). Como conclusão os parâmetros de temperatura do metal e velocidade de primeira e segunda fase de injeção foram os mais significativos na redução da porosidade da peça estudada. E ainda, o método de Taguchi alcançou o resultado esperado, trazendo significativa redução de porosidade na peça estudada por meio da otimização dos parâmetros do processo.
\end{abstract}

Palavras-chave: Método de Taguchi. Fundição sob pressão. Relação sinal-ruído ponderada. Porosidade.

Abstract: The aluminum die casting process has developed significantly in recent decades, occupying a prominent place for producing innovative engineering components. Among quality problems of this process is porosity due to several factors, including the process parameters that are difficult to determine, and are commonly selected by trial and error approach. This paper sought to answer the question: How to determine the best set of parameters of the aluminum die casting process to minimize porosity in the parts produced? Aiming to improve die casting aluminum parts quality through reducing of porosity. The main contribution of this paper focuses on the application of Taguchi method using ordinal categorical data (porosity classes) as a quality characteristic, by analyzing the weighted signal-to-noise ratio. The experimental results were analyzed from the average effect of factors and analysis of variance (ANOVA). In conclusion parameters metal temperature and speed of the first and second injection phase were the most significant in reducing the porosity of the part studied. Also, the Taguchi method achieved the expected result, bringing significant reduction of porosity in the part studied by optimizing the process parameters.

Keywords: Taguchi method. Die casting. Weighted signal-to-noise ratio. Porosity. 


\section{INTRODUÇÃO}

As peças produzidas no processo de fundição sob pressão (FSP) são atualmente vistas como componentes de engenharia inovadora, que possibilitam redução de custos em processos posteriores e redução de peso. Dentre os processos de fundição de alumínio, a FSP é o processo mais utilizado globalmente, contabilizando cerca de $70 \%$ da produção de peças fundidas em alumínio (APELIAM e MAKHLOUF, 2006).

Embora o processo de FSP possua várias vantagens, componentes fabricados neste processo apresentam sérias limitações devido sua porosidade. A porosidade pode ocorrer pela contração do metal durante a solidificação, ou ainda por gases, que podem estar dissolvidos no metal fundido ou serem inclusos durante o preenchimento do molde (BREVICK, 2009). Como consequências da porosidade ocorrem a diminuição da resistência mecânica, o favorecimento de trincas e o vazamento em peças que contêm fluidos sob pressão (MENDES, 2005).

Os defeitos de porosidades são em grande parte consequência do projeto do produto e do molde, mas os parâmetros do processo de FSP também têm grande influência na criação da porosidade (KIRKMAN, 2006). Por existirem vários fatores do processo que influenciam na porosidade das peças, a determinação dos parâmetros ideais, que minimizam o problema, não é feita facilmente. Esta abordagem experimental não estruturada, mesmo feita por profissionais experientes, nem sempre é eficaz, devido ao grande número de fatores envolvidos e as variações decorrentes de parâmetros sem controle (MONTGOMERY, 2009).

Neste contexto, torna-se relevante pesquisar: Como determinar a melhor configuração de parâmetros do processo de fundição sob pressão de alumínio para minimizar a porosidade das peças produzidas.

O presente trabalho tem como objetivo a melhoria da qualidade de uma peça de alumínio, fundida sob pressão, por meio da redução da porosidade. Este estudo não pretende abordar a análise de parâmetros do projeto do produto e do molde, assumindo como premissa que foram utilizadas técnicas corretas para o projeto de ambos, sendo objeto do estudo a utilização do método de Taguchi no planejamento 
experimental do processo de fundição sob pressão para a determinação dos parâmetros de processo que reduzem a porosidade das peças produzidas.

A pesquisa foi realizada em uma empresa metalúrgica multinacional, com matriz na Alemanha, fabricante de moto-redutores, a qual possui uma fundição de alumínio sob pressão como um de seus setores produtivos. O setor de fundição de alumínio da empresa é composto por quatro injetoras de alumínio, responsáveis por fundir cerca de 50 modelos de peças de diversos tamanhos e complexidades, correspondendo a um volume mensal de 55 toneladas de alumínio.

Para os experimentos foi utilizada uma injetora do fabricante Bühler, modelo Evolution B53 Compact, com 530 toneladas de força de fechamento, com controle eletrônico da curva de injeção, integrada a um forno dosador do fabricante StrikoWestofen $\mathrm{GmbH}$, modelo Westomat ${ }^{\circledR}$ 1200S, com controle eletrônico de controle de temperatura, dosagem e sistema de desgaseificação por plugs porosos acoplado. Para a aplicação de desmoldante foi utilizado um aplicador automático do fabricante Acheson, modelo MCT1, integrado à injetora.

A principal contribuição deste artigo concentra-se na aplicação do método de Taguchi utilizando dados categóricos ordinais como característica de qualidade, já que o projeto robusto de Taguchi é geralmente empregado utilizando como característica de qualidade variáveis continuas, mas a utilização de dados categóricos ordinais também encontra diversas aplicações por serem muitas vezes de obtenção mais simples e menos dispendiosa.

O presente trabalho foi organizado da seguinte forma:

- No capítulo 2 são apresentados trabalhos realizados por diversos autores abordando o processo de fundição sob pressão, os tipos de porosidades ocorrentes em peças fundidas neste processo e suas principais causas, e o planejamento de experimentos utilizando o método de Taguchi.

- O capítulo 3 descreve os procedimentos experimentais, apresentando a sequencia de elaboração da pesquisa, estabelecendo os parâmetros de processo como as variáveis de entrada, assim como os níveis adotados e o arranjo experimental utilizado. Também é apresentada a forma de mensuração da variável resposta, a porosidade, assim como as formas de análise experimental utilizada. 
- No capítulo 4 são apresentados os resultados das classificações de porosidade das peças agrupados por categorias, os sinais-ruídos para cada rodada de experimentos, assim como o efeito médio decorrente de cada nível de fator. A análise de variância (ANOVA) é realizada para estabelecer os fatores relevantes.

- No capitulo 5 são apresentadas as conclusões dos experimentos realizados.

\section{REVISÃO DA LITERATURA}

Neste capitulo são apresentados conceitos referentes a fundição sob pressão, formação de porosidades nas peças fundidas, o método de Taguchi e a análise de dados categóricos ordinais.

A literatura relata diversos casos de aplicação do método de Taguchi no estudo dos parâmetros do processo de fundição sob pressão. No entanto, nos trabalhos que estudam a redução de porosidade é utilizada, predominantemente, a medição da porosidade por meio da densidade das peças. Não se encontrou trabalhos que relacionam classes de porosidade ao método de Taguchi.

Anastasiou (2002) e Syrcos (2003) utilizaram o método de Taguchi para investigar a influencia dos parâmetros do processo de fundição sob pressão na formação da porosidade nas peças. Em ambos os estudos a pressão de compactação foi o parâmetro que mais influenciou na porosidade das peças.

Wu e Chang (2004) aplicou o método de Taguchi para otimizar os parâmetros do processo de fundição de ligas de magnésio em peças de paredes finas. $O$ estudo relacionou o empenamento da superfície da peça com os parâmetros do processo, $O$ estudo revelou que a temperatura do molde e o uso de resfriamento natural têm grande influencia no empenamento das peças.

Vijian e Arunachalam (2006) utilizou o método de Taguchi para estudar a influência dos parâmetros de processo de fundição por pressão na rugosidade superficial das peças. Os resultados indicaram que a pressão de compactação e a temperatura de pré-aquecimento do molde apresentam maior influência na melhoria da rugosidade. 
Savas e Kayikci (2007) estudou a relação entre a microporosidade e as variáveis de processo do processo de fundição em areia da liga de alumínio A360, utilizando o método de Taguchi. Os resultados mostraram que o tempo de solidificação local e o nível de hidrogênio dissolvido no material fundido foram os fatores mais significantes para o surgimento de microporosidade.

Com o objetivo de compreender melhor o fenômeno de formação de porosidades nas peças fundidas sob pressão e suas consequências, buscou-se na literatura estudos relacionados ao assunto, sendo citados alguns autores a seguir.

Ammar, Samuel e Samuel (2008) estudaram o comportamento de cinco ligas de Al-Si sob a influência de heterogeneidades microestruturais e submetidas a testes de fadiga. Após a análise das fraturas, concluíram que o defeito de porosidade foi o principal responsável pela diminuição da vida das peças nos teste de fadiga, sendo que $90 \%$ das amostras tiveram fraturas originadas deste defeito.

Wang, Turnley e Savage (2011) apresentaram um estudo onde os níveis de porosidade resultante de gás de varias peças fundidas sob pressão foram quantificados utilizando o método de fusão a vácuo. O estudo revelou que a maior parte da porosidade de gás é resultante de aprisionamento de gases durante o preenchimento da cavidade.

Faura, López e Hernández (2001) analisaram a aceleração do pistão durante a primeira fase de injeção do processo de fundição sob pressão, buscando minimizar o aprisionamento de ar, e consequentemente, reduzir a porosidade das peças produzidas.

Dargusch et al. (2006) investigaram a influência da pressão durante a solidificação no processo de fundição sob pressão. Segundo os autores, a porosidade diminui com o aumento da pressão e aumenta com o aumento da velocidade de injeção.

\subsection{0 processo de fundição de alumínio sob pressão}

O processo de FSP é o que mais se destaca dentre os processos de fundição de alumínio, sendo durante muito tempo restrito a utensílios domésticos, componente de eletrodomésticos e de equipamento de escritório. Na década de 70 , 
com a crise do petróleo, as indústrias automobilísticas foram obrigadas a buscar alternativas para tornar os carros mais leves, consumindo menos combustível, sendo as ligas de alumínio uma boa opção por possuir o peso bem menor que o aço. Diversas dessas aplicações são ilustradas na Figura 1. Inicialmente as peças em ligas de alumínio se restringiam a aplicações de menor importância na indústria automobilística, como frisos, suportes e maçanetas, mas atualmente já vem sendo utilizadas em aplicações mais críticas como blocos de motor (MEDEIROS, 2009), como ilustra a Figura 2.

Figura 1 - Algumas aplicações de peças fundidas sob pressão em automóveis

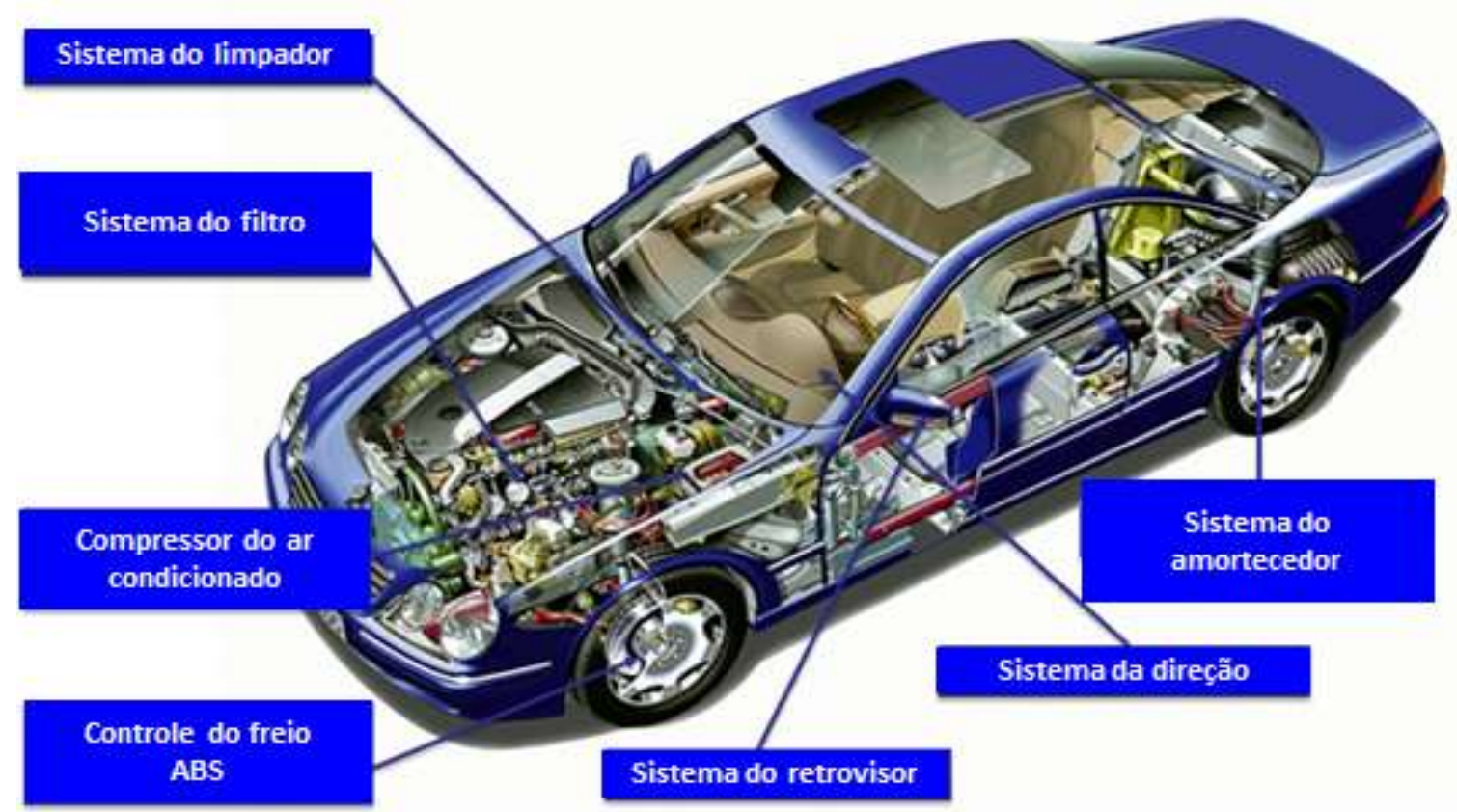

Fonte: IKD Auto Products (2012) 
Figura 2 - Bloco de motor de alumínio e magnésio da BMW.

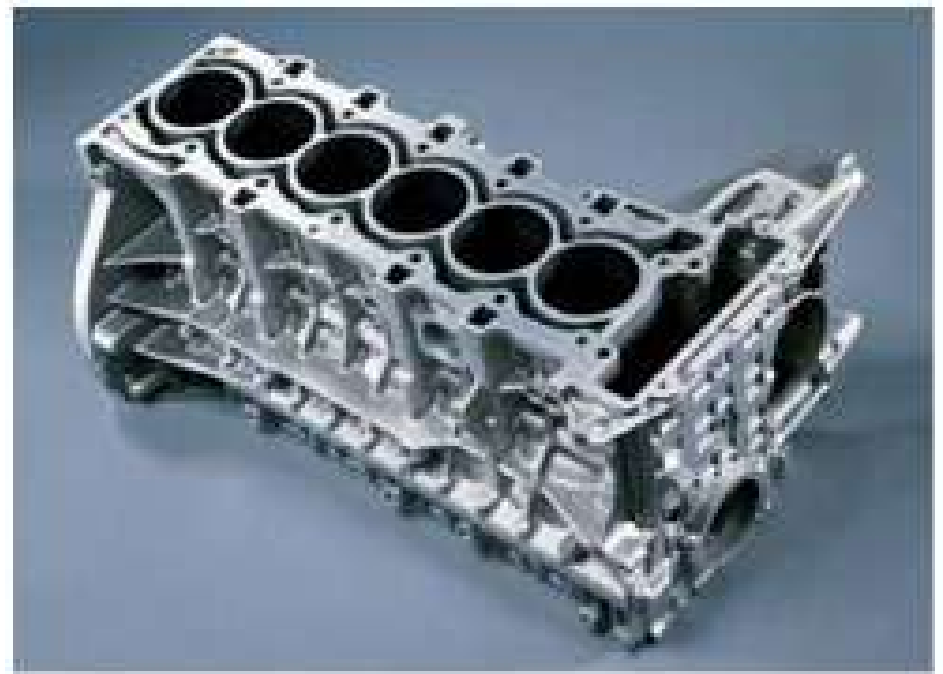

Fonte: Aluinfo (2012)

O processo de fundição sob pressão consiste em injetar um metal liquido (liga de alumínio, zinco ou magnésio) contido em um recipiente para o interior da cavidade de um molde, submetendo o metal a altas pressões. O processo é dividido em dois tipos de acordo com o sistema de injeção utilizado: câmara quente ou fria (MALAVAZI, 2005). O presente trabalho se restringirá ao processo de câmara fria.

A Figura 3 ilustra as etapas do ciclo do processo de FSP, onde, com o molde fechado, o metal líquido é vazado na câmara de injeção alojada na parte fixa do molde (Figura 3a), o pistão de injeção avança lentamente para retirar os gases da câmara de injeção (Figura 3b), avança rapidamente para preencher a cavidade do molde (Figura 3c), aplica uma elevada pressão sob o metal durante sua solidificação (Figura 3d) e após a abertura do molde (Figura 3e) a peça é extraída por pinos localizados na parte móvel do molde (Figura 3f) (MALAVAZI, 2005 e VINARCIK, 2003). 
Figura 3 - Etapas do processo de FSP
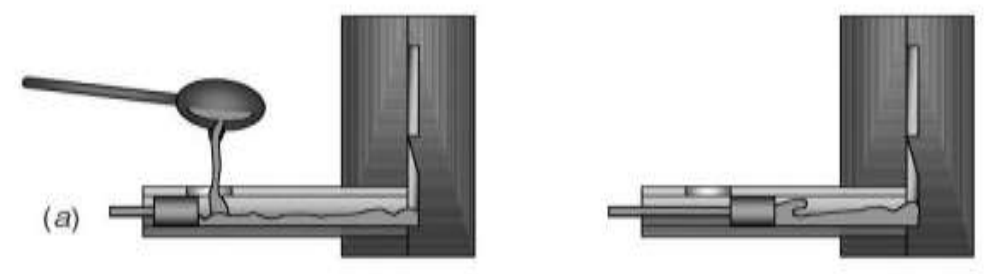

(b)

(c)
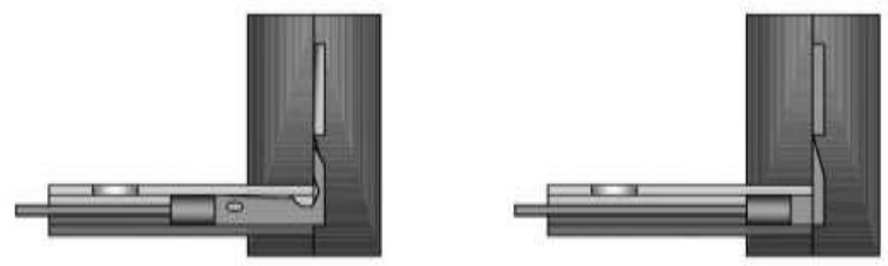

(d)

(e)
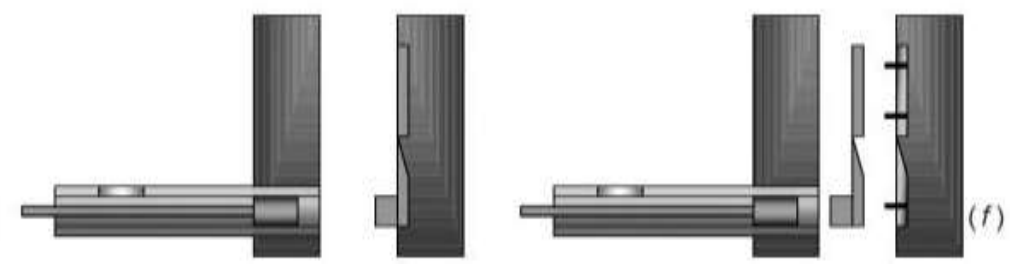

Fonte: Vinarcik (2003)

\subsection{A porosidade no processo de Fundição sob pressão de alumínio}

As porosidades são vazios ou poros preenchidos com gases onde deveria existir metal, e devido à natureza física dos metais, as peças fundidas tendem a ter porosidade. As razões mais comuns para o surgimento da porosidade são a contração devido à solidificação e a presença de gases no metal fundido (BREVICK, 2009).

Segundo Vinarcik (2003), vários estudos têm demonstrado como a porosidade varia com as diversas condições operacionais, e que a quantidade total de porosidade em um componente é função da contração devido à solidificação e da presença de gases inclusos. A contração resultante da solidificação é uma característica dos metais e a inclusão de gases ocorre devido às condições do processo de fundição. Na Figura 4 são mostrados os formatos característicos dos poros encontrados em peças fundidas em função da causa predominante. 


\section{Porosidade}

a) Contração

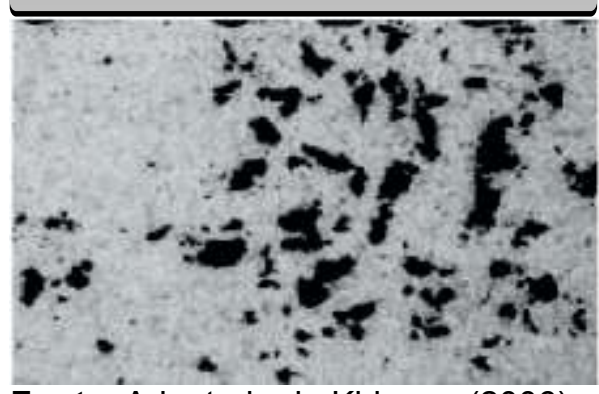

Fonte: Adaptado de Kirkman (2006) b) Gases

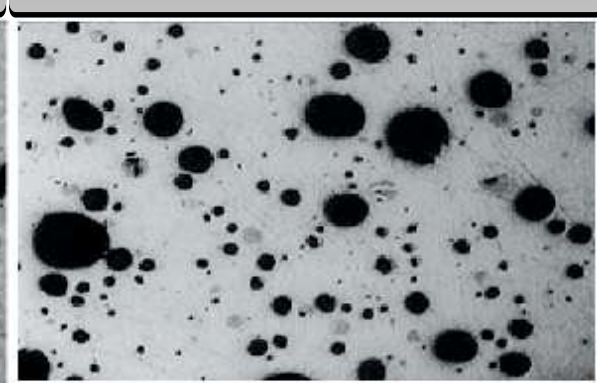

\subsubsection{Porosidade por contração}

Porosidade por contração ou rechupe são vazios em peças fundidas que surgem devido à mudança volumétrica que ocorre durante a solidificação das ligas fundidas. Os poros têm formato irregular não esférico, e o metal ao seu redor tem aparência dendrítica. A Figura 4a ilustra a forma dos poros causados por contração (KIRKMAN, 2006).

A ocorrência deste tipo de porosidade está associada à transferência de calor do molde e ao sistema de alimentação da cavidade, sendo mais frequente em regiões de maior espessura, onde não é possível compensar a contração do material por meio dos canais de entrada, que se solidificam rapidamente (MALAVAZI, 2005).

Em relação aos parâmetros do processo, a temperatura do molde é o fator mais crítico para o controle da localização dos rechupes, bem como do tempo em que a alimentação de metal é mantida alimentando uma determinada seção do material. Um fator de grande influencia na temperatura do molde é o ritmo de trabalho, que deve ser constante, evitando-se variações no tempo de ciclo da máquina (MALAVAZI, 2005 e KIRKMAN, 2006).

Outro parâmetro importante é a pressão de compactação, que é aplicada depois da injeção, e mantida durante o tempo de solidificação. $O$ tempo de subida desta pressão deve ser o menor possível, pois a seção do canal de ataque se solidifica rapidamente após o fim da injeção, impedindo que mais material seja injetado para compensar a contração da liga (MALAVAZI, 2005 e KIRKMAN, 2006). 


\subsubsection{Porosidade por gases}

A porosidade por gases é provavelmente o tipo mais comum de porosidade em peças fundidas sob pressão, e sua aparência se distingue da porosidade por contração por apresentar formato circular (bolhas) na seção em corte, com o fundo liso e brilhante na grande maioria dos casos. A Figura 4b ilustra a forma dos poros causados por gases. Ainda que o metal seja submetido a grandes pressões durante a solidificação, devido à relação geométrica entre pressão e tamanho das bolhas, a partir de pressões mais elevadas o tamanho das bolhas diminui pouco, e ainda causam como consequência o aumento de rebarbas (WALKINGTON, 2006). são:

Segundo Walkington (2006) as principais causas deste tipo de porosidade

Ar aprisionado: É a causa mais provável devido a grande turbulência do fluxo e rápida taxa de preenchimento necessária ao processo. Parâmetros como grau de enchimento da câmara, velocidade lenta de injeção, saídas de ar, projeto dos canais de alimentação e área de ataque influenciam diretamente na quantidade de ar aprisionado.

Vapor e gás de lubrificante vaporizado: antes de introduzir o metal líquido deve-se garantir que o molde está totalmente seco utilizando-se sistemas de sopro adequados. A fonte mais frequente de vapores é a mistura desmoldante a base de água, principalmente quando utilizada em excesso com a função de controlar a temperatura do molde. Outras fontes comuns são vazamentos de linhas de refrigeração e lubrificantes de pistão, quando aplicados diretamente no interior da câmara de injeção.

Gás hidrogênio: devido à composição das ligas e as temperaturas comuns utilizadas no processo de fundição sob pressão, cerca de $680^{\circ} \mathrm{C}$, a solubilidade do hidrogênio é baixa, representando cerca de 5 a $10 \%$ da porosidade por gás. Os esforços na redução da porosidade devem ser focados nas outras fontes de ar ou gás até que o gás hidrogênio se torne um problema significante.

Malavazi (2005) também destaca fatores operacionais como movimento irregular do pistão injetor, obstrução de saídas e bolsas de gases como pontos relevantes de aprisionamento de gases, e portanto, formação de porosidade. 


\subsection{Os Métodos de Taguchi}

No campo da ciência de planejamento de experimentos, Taguchi (1986) propôs métodos que simplificaram e padronizaram os experimentos fatoriais fracionados. Os métodos propostos podem ser facilmente aplicados em ambiente industrial, e obtém resultados consistentes para um mesmo experimento realizado por diferentes investigadores (ROY, 2010).

Segundo Roy (2010), com o objetivo de tornar o DOE mais simples e atrativo à indústria, Taguchi propôs:

a) Estratégia do Projeto Robusto: para fazer produtos e processo insensíveis aos fatores não-controláveis (ruídos), Taguchi propôs uma forma de incluir os fatores não-controláveis no planejamento de experimentos.

b) Função perda: fórmula matemática proposta por Taguchi para quantificar de forma monetária as economias oriundas da aplicação do DOE, e consequente redução da variação.

c) Padronização do DOE: utilização de tabelas especiais, chamadas de arranjos ortogonais, que representam o menor experimento fatorial fracionado possível.

d) Análise de Sinal-Ruído (S/R): a relação sinal-ruído como uma métrica da robustez de um produto ou processo, permitindo analisar a relação entre a característica desejada e as indesejadas.

\subsubsection{Projeto Robusto}

Segundo Taguchi e Clausing (1990) projeto robusto é o conceito de se pensar em produtos que resultem na mínima perda para a sociedade em todas as fases do projeto e do processo.

Taguchi considera que o desenvolvimento do produto ou processo se divide em três etapas (EALEY, 1994):

- $\quad$ Projeto de sistema: é a etapa em que a arquitetura básica do produto ou processo é determinada, e tem o objetivo de fornecer aos 
consumidores produtos novos e aperfeiçoados, utilizando novos conceitos, ideias, métodos, etc. Os métodos de Taguchi geralmente não são utilizados nesta etapa.

- $\quad$ Projeto por parâmetros: tem a função de aperfeiçoar o desempenho do projeto do sistema por meio de experimentações, a fim de minimizar as variações resultantes dos fatores não controláveis dos usuários ou do ambiente e, desta forma, garantir a uniformidade do produto ou processo.

- $\quad$ Projeto por tolerâncias: nesta etapa, a qualidade é aperfeiçoada reduzindo-se a tolerância dos parâmetros dos produtos ou processo, e consequentemente, diminuindo a variação no desempenho. Normalmente é utilizado apenas quando o Projeto por parâmetros não é suficiente para reduzir as variações do produto ou processo, já que reduzir tolerâncias implica quase sempre em altos custos com materiais e equipamentos.

\subsubsection{Função Perda de Qualidade}

Segundo Roy (2010) a função perda de qualidade (FPQ) tem o objetivo primário de estimar a economia resultante da melhoria da qualidade, considerando todas as fases do ciclo de vida de um produto. O custo da qualidade não atendida ocorre sempre que os valores objetivos não são atingidos, e devem ser medidos em um sistema amplo e não somente de forma local, pois além de custos nas fases de desenvolvimento e fabricação, podem geram custos maiores com manutenção, suspensão temporária de funcionamento e perda de negócios no decorrer de seu ciclo de vida (NETO, 1997).

Segundo Ross (1991), a função perda de Taguchi é aplicada de acordo com a característica de qualidade desejada, podendo ser do tipo:

a) Nominal-é-melhor: são as características funcionais que apresentam 0 valor nominal como o mais desejado pelo cliente. Podem-se citar, como exemplo, características como dimensão, pressão, viscosidade, cor de um produto, força e a composição química de um material. Sua FPQ é dada pela Equação 1. 


$$
L(y)_{N \in M}=k\left(y-y_{0}\right)^{2}
$$

Onde:

$L(y)_{N \in M}=$ função perda da qualidade tipo nominal-é-melhor

$k=$ constante de custo

$y_{i}=$ característica mensurável do produto ou do processo em nível $i$

$y_{0}=$ característica nominal do produto ou do processo

b) Menor-é-melhor: são as características funcionais que apresentam o valor zero como o mais desejado pelo cliente. Como exemplos podem ser citadas características como nível de impureza, desgaste, deterioração, consumo de combustível e tempo de espera. Pode-se observar que tal fenômeno também ocorre com a porosidade, que é a característica estudada neste trabalho, visto que quanto menor o nível de porosidade maior será a resistência mecânica e a estanqueidade do produto.

A FPQ da característica menor-é-melhor é dada pela Equação 2:

$$
L(y)_{m e M}=k y^{2}
$$

Onde:

$L(y)_{m e M}=$ função perda da qualidade tipo menor-é-melhor

$k=$ constante de custo

$y_{i}=$ característica mensurável do produto ou do processo em nível $i$

c) Maior-é-melhor: são as características funcionais que quanto maior mais desejado pelo cliente. Exemplos deste tipo de característica são a resistência mecânica, aderência de adesivos, vida útil e rendimento de combustíveis. A FPQ desta característica é dada pela Equação 3.

$$
L(y)_{M e M}=k \frac{1}{y^{2}}
$$

Onde:

$L(y)_{M \in M}=$ função perda da qualidade

$k=$ constante de custo

$y_{i}=$ característica mensurável do produto ou do processo em nível $i$ 


\subsubsection{Determinação do coeficiente $k$}

Segundo Ealey (1994), para a determinação do coeficiente $k$ da FPQ é necessário considerar as características de desempenho do produto ou de variação do processo que são mais críticas para o consumidor, pois a taxa de aumento da perda depende da relevância financeira da característica da qualidade considerada. Se a característica é, por exemplo, uma dimensão crítica de um dispositivo de segurança de um reator nuclear, a perda aumentará muito rapidamente com o desvio da característica do valor objetivo. Por isso, a equação da FPQ deve refletir a gravidade das consequências da variação para o consumidor.

O coeficiente $k$ representa a relevância financeira devido ao desvio do objetivo para o consumidor, e pode ser estimado pela Equação 4.

$$
k=\frac{A_{0}}{\Delta_{0}^{2}}
$$

Onde:

$k=$ constante de custo

$A_{0}=$ Perda para o consumidor

$\Delta_{0}=$ Tolerância funcional

A tolerância funcional $\left(\Delta_{0}\right)$ é o máximo valor permissível de desvio para o valor objetivo de uma característica devido ao qual um produto médio não funciona, representando o ponto de vista de um consumidor médio (EALEY, 1994).

A perda para o consumidor $\left(A_{0}\right)$ é a perda média resultante quando o desvio da característica excede a tolerância funcional, representando o custo médio para o consumidor substituir ou consertar o produto, com sua insatisfação associada (EALEY, 1994).

\subsubsection{Relação Sinal-Ruído}

Segundo Montgomery (2009), o processo pode ser visualizado como uma combinação de máquinas, métodos, pessoas e outros recursos, que transformam insumos em uma saída com uma ou mais respostas observáveis. Algumas das variáveis do processo são controláveis, outras não. 
Dentre as variáveis controláveis, pode-se citar o material, tempo de ciclo ou temperatura de fundição. As variáveis não controláveis são classificadas como ruído, por exemplo, temperatura ambiente, umidade relativa, etc., muito embora esses fatores possam ser controlados para efeito de experimentos (EALEY, 1994).

Sendo assim, a resposta do sistema é influenciada tanto pelos fatores controláveis, como pelos ruídos. Desta forma, pode-se aplicar o termo relação sinalruído análogo ao original utilizado em telecomunicação, como medida da qualidade da resposta (EALEY, 1994). Segundo Neto (1997) e Ross (1991) a relação sinalruído no contexto da Qualidade procura observar ao mesmo tempo a média e a variância da resposta, reunindo em um único número o desempenho do processo ou produto.

\subsubsection{Padronização do DOE - Arranjos Ortogonais}

Segundo Montgomery (2009), por planejamento fatorial entende-se que em cada rodada completa de experimento sejam investigadas todas as combinações dos níveis de todos os fatores. No entanto, em projetos de engenharia com muitos fatores, os custos envolvidos tornam experimentos com todos os fatores proibitivos, sendo necessário reduzir o número de testes por meio de experimentos fatoriais fracionados. Por esta razão Taguchi desenvolveu configurações especiais de experimentos fracionados, chamados de Arranjos Ortogonais (AO), que ajudam a determinar o número mínimo de experimentos para um determinado número de fatores (ROY, 2010).

Segundo Roy (2010), os AO de Taguchi são identificados pela letra "L" seguida de um número que indica a quantidades de experimentos, como por exemplo, o arranjo ortogonal L4 que necessita de 4 experimentos e permite a utilização de dois níveis para cada fator. A Tabela 1 indica alguns tipos de AO, 0 número de níveis possíveis para cada fator e o número máximo de fatores. A seleção do arranjo mais adequado ao planejamento do experimento é feita com base na quantidade de fatores e interações que se deseja estudar. 
Tabela 1 - Alguns tipos de AO de Taguchi

\begin{tabular}{cccc}
\hline $\begin{array}{c}\text { Arranjo } \\
\text { Ortogonal }\end{array}$ & $\begin{array}{c}\text { Número de } \\
\text { Ensaios }\end{array}$ & $\begin{array}{c}\text { Número de } \\
\text { Níveis }\end{array}$ & $\begin{array}{c}\text { Número } \\
\text { Máximo de } \\
\text { Fatores }\end{array}$ \\
\hline L4 & 4 & 2 & 3 \\
L8 & 8 & 2 & 7 \\
L9 & 9 & 3 & 4 \\
L12 & 12 & 2 & 11 \\
L16 & 16 & 2 & 15 \\
L18 & 18 & 3 & 8 \\
L27 & 27 & 3 & 13 \\
L32 & 32 & 2 & 31 \\
\hline
\end{tabular}

Fonte: Adaptado de Ross (1991)

\subsubsection{Análise de Variância (ANOVA)}

A análise de variância é a técnica estatística utilizada neste artigo para medir a grau de confiança de dados. Esta técnica não analisa os dados diretamente, mas sim determina sua variabilidade, sendo aplicada para determinar a influência dos parâmetros de entrada nos resultados experimentais, permitindo assim a interpretação dos dados.

As variâncias $\left(V_{i}\right)$ e porcentagens de contribuição $(P)$, pertencentes a tabela ANOVA, são utilizados na avaliação da significância dos fatores em relação a variação total do experimento. E a taxa de variância $(F)$ permite atribuir um nível de confiança estatística a análise.

\subsection{Dados categóricos ordinais}

Segundo Veloso (2009) dados categóricos são aqueles que podem ser classificados em categorias, como por exemplo a qualidade de um produto na opinião do cliente que pode ser classificada como "muito ruim", "ruim", "razoável", "boa" ou "muito boa". Quando estes dados possuem uma ordenação natural são chamados de ordinais. Outra forma de estabelecer dados categóricos ordinais é dividir variáveis contínuas em intervalos obtendo-se categorias, definidas por constantes chamadas de pontos de corte. Neste trabalho são utilizadas categorias 
de porosidade ordenadas de forma crescente para a classificação da variável de resposta dos experimentos, como será detalhado mais adiante.

Segundo Wu (2006) os dados observados em muitos experimentos são categóricos ordinais devido à característica de qualidade analisada ou a conveniência da técnica de medição, como é o caso deste estudo.

Chipman e Hamada (1993) exemplifica a necessidade de utilização de dados categóricos ordinais com o exemplo da medição da força necessária para fechar uma porta, que embora existam dispositivos que possam fazer está medição, eles podem ser caros e consumir muito tempo. Desta forma, um especialista pode ser utilizado para fazer um julgamento categórico, tal como "difícil”, "aceitável" e "fácil".

\subsubsection{Relação Sinal-Ruído Ponderada}

Wu e Yeh (2006) apresentaram um estudo comparativo entre quatro métodos de análise de dados categóricos ordinais para otimização de fatores experimentais, onde se destaca o método de Relação Sinal-Ruído Ponderada (RSRP) ou Weighted Signal-to-Noise Ratio (WSNR), por sua simplicidade e eficiência na obtenção dos fatores ótimos em um único passo. Este método será utilizado no presente trabalho, considerando como característica de qualidade estudada a porosidade das peças fundidas classificada de acordo com o nível apresentado nas regiões críticas.

Neste método, um peso proporcional à perda de qualidade é atribuído a cada categoria. A resposta categórica é usada como se fosse continua e analisada por meio da relação sinal-ruído (RSR) do tipo menor-é-melhor. Os níveis de parâmetros ótimos são os que resultam na maior RSR (YENIDUNYA, 2009; WU e YEH, 2006).

Segundo Wu e Yeh (2006) a RSRP é dada pela Equação 5:

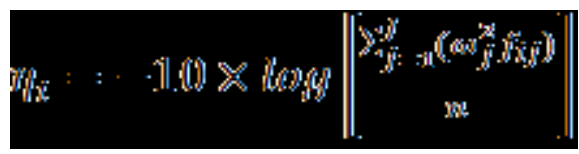

Onde:

$\eta_{i}$ : relação sinal-ruído da rodada de experimento $i$ em decibéis (dB)

$n$ : número total de observações

$\omega_{j}$ : peso atribuído à $j$-ésima categoria 
$f_{i j}$ : frequência observada na $j$-ésima categoria para o $i$-ésima rodada de experimento.

\section{PROCEDIMENTOS METODOLÓGICOS}

A pesquisa foi realizada utilizando-se a sequência apresentada por Ribeiro (2008) na condução de experimentos utilizando o método de Taguchi. A Figura 5 ilustra os passos seguidos, iniciando-se com a definição das variáveis de entrada e passando por todas as etapas até o experimento de confirmação, o qual verifica se a otimização dos parâmetros obteve o resultado esperado.

Figura 5 - Sequencia de Elaboração de Experimento

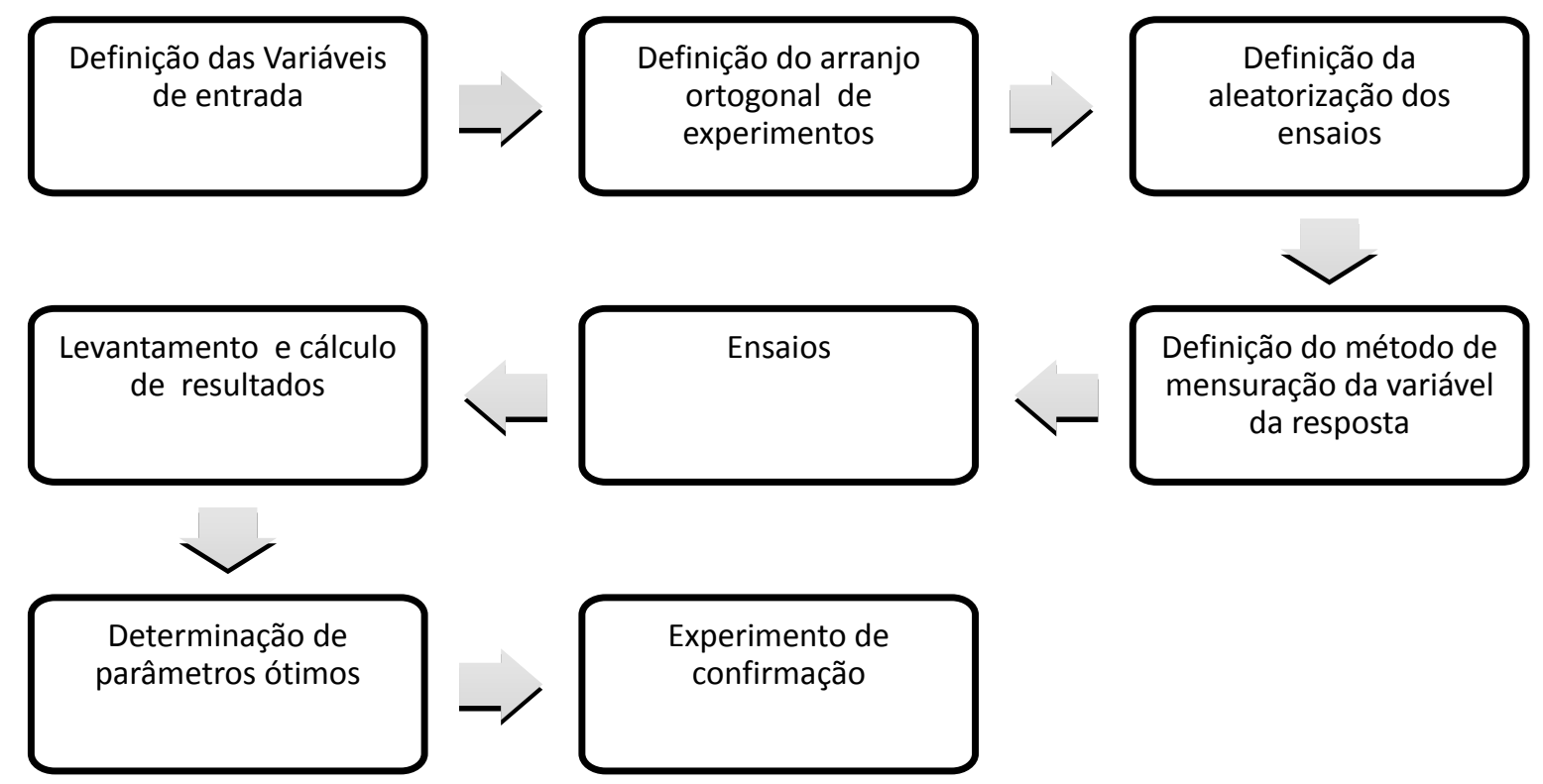

Fonte: Adaptado de Ribeiro (2008)

\subsection{Definição das variáveis de entrada}

A definição das variáveis de entrada foi feita a partir da análise do diagrama de Causa-Efeito, ilustrado na Figura 6 com os fatores do processo que poderiam ter influência no surgimento da porosidade. Abordagem semelhante foi feita por Syrcos (2003), Wu e Chang (2004) e Anastasiou (2002). 
Figura 6 - Diagrama de Causa e Efeito das variáveis do processo automatizado

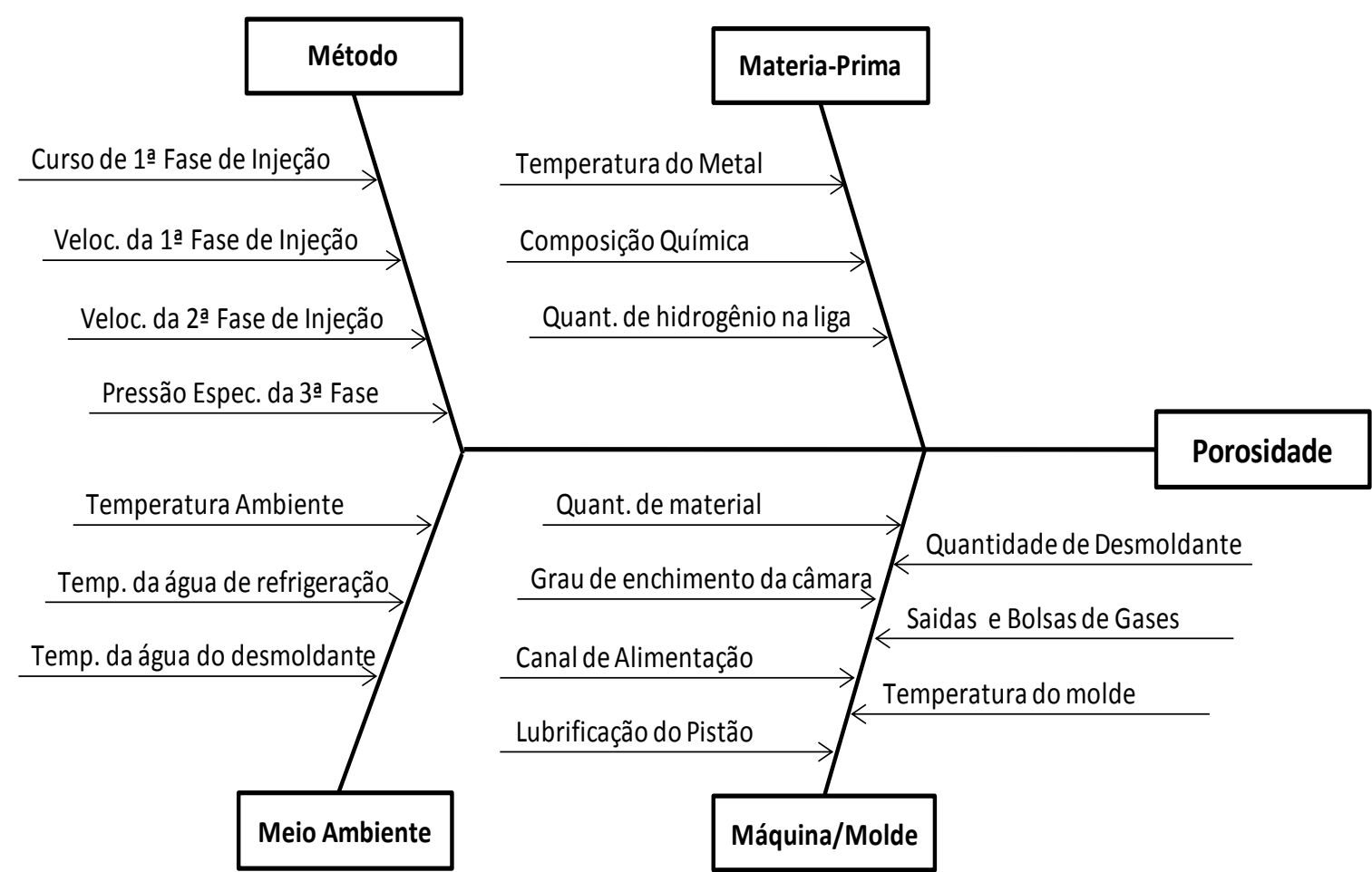

Entre os fatores controláveis no processo, que não exigiam alterações no projeto do molde, foram selecionados seis parâmetros, sendo eles:

- Temperatura do metal

- Velocidade da segunda fase de injeção

- Velocidade da primeira fase de injeção

- Pressão específica da terceira fase de injeção

- Curso da primeira fase de injeção

- Temperatura do molde

\subsection{Definição do arranjo ortogonal}

A partir da escolha dos seis parâmetros foram designados 2 níveis para cada um, conforme Tabela 2, o que levou à adoção de uma matriz ortogonal L8, com oito rodadas de experimentos e quatro réplicas de cada, por ser o arranjo experimental com o menor número de experimentos possíveis para seis fatores. 
Tabela 2 - Fatores e níveis dos experimentos

\begin{tabular}{clcc}
\hline Fator & Descrição & Nível 1 & Nível 2 \\
\hline A & Temperatura do metal $\left({ }^{\circ} \mathrm{C}\right)$ & 680 & 725 \\
B & Velocidade da 2a Fase de injeção $(\mathrm{m} / \mathrm{s})$ & 3,8 & 4,2 \\
C & Velocidade da 1a Fase de injeção $(\mathrm{m} / \mathrm{s})$ & 0,2 & 0,6 \\
D & Pressão Especifica da 3a Fase de injeção (BAR) & 800 & 1000 \\
E & Curso da 1 1a Fase de injeção $(\mathrm{mm})$ & 240 & 270 \\
F & Temperatura do molde $\left({ }^{\circ} \mathrm{C}\right)$ & 180 & 220 \\
\hline
\end{tabular}

Na Tabela 3 é mostrada a combinação de níveis de parâmetros (1 ou 2) em cada experimento. Conforme a sequência de passos proposta, os experimentos foram aleatorizados, conforme indicado na coluna de sequência.

Tabela 3 - Combinação de níveis de fatores

\begin{tabular}{cccccccc}
\hline AO L8 & \multicolumn{7}{c}{ Fatores } \\
\hline Experimento & Seq. & A & B & C & D & E & F \\
\hline 1 & 7 & 1 & 1 & 1 & 1 & 1 & 1 \\
2 & 5 & 1 & 1 & 2 & 2 & 2 & 2 \\
3 & 8 & 1 & 2 & 1 & 1 & 2 & 2 \\
4 & 6 & 1 & 2 & 2 & 2 & 1 & 1 \\
5 & 1 & 2 & 1 & 1 & 2 & 1 & 2 \\
6 & 3 & 2 & 1 & 2 & 1 & 2 & 1 \\
7 & 2 & 2 & 2 & 1 & 2 & 2 & 1 \\
8 & 4 & 2 & 2 & 2 & 1 & 1 & 2 \\
\hline
\end{tabular}

De acordo com a configuração experimental do arranjo ortogonal L8, mostrado na Tabela 3 , foram feitas 8 rodadas de experimentos. Para assegurar a exatidão dos resultados, foram feitos 20 ciclos em cada configuração experimental, sendo utilizadas apenas as peças dos quatro últimos ciclos, permitindo assim que o processo se estabilizasse termicamente e que as peças fossem representativas do processo em ritmo normal de produção.

\subsection{Medição da variável de resposta}

Após a realização dos experimentos, as peças foram usinadas e quatro áreas foram analisadas e classificadas de acordo com a quantidade e tamanho dos poros, 
conforme as categorias mostradas na Figura 7. Conforme foi exposto anteriormente, a variável de resposta analisada neste trabalho é a porosidade. Na classificação das regiões usinadas de acordo com uma escala de categorias de poros são consideradas seis categorias, onde 0 corresponde a categoria de uma região isenta de poros e as categorias de 1 a 5 correspondem a tamanhos de poros crescentes, sendo a categoria 5 a que possui os maiores poros. Um padrão de comparação visual, em escala 1:1 é indicado em cada classe, onde também são indicados os tamanhos, distâncias aproximadas entre poros e distribuição de poros em relação às áreas utilizados como referencia. Um modo similar de classificação de porosidade em regiões usinadas é utilizado por Brevick (2009) e Zhao (2009).

Figura 7 - Categorias para classificação de porosidade

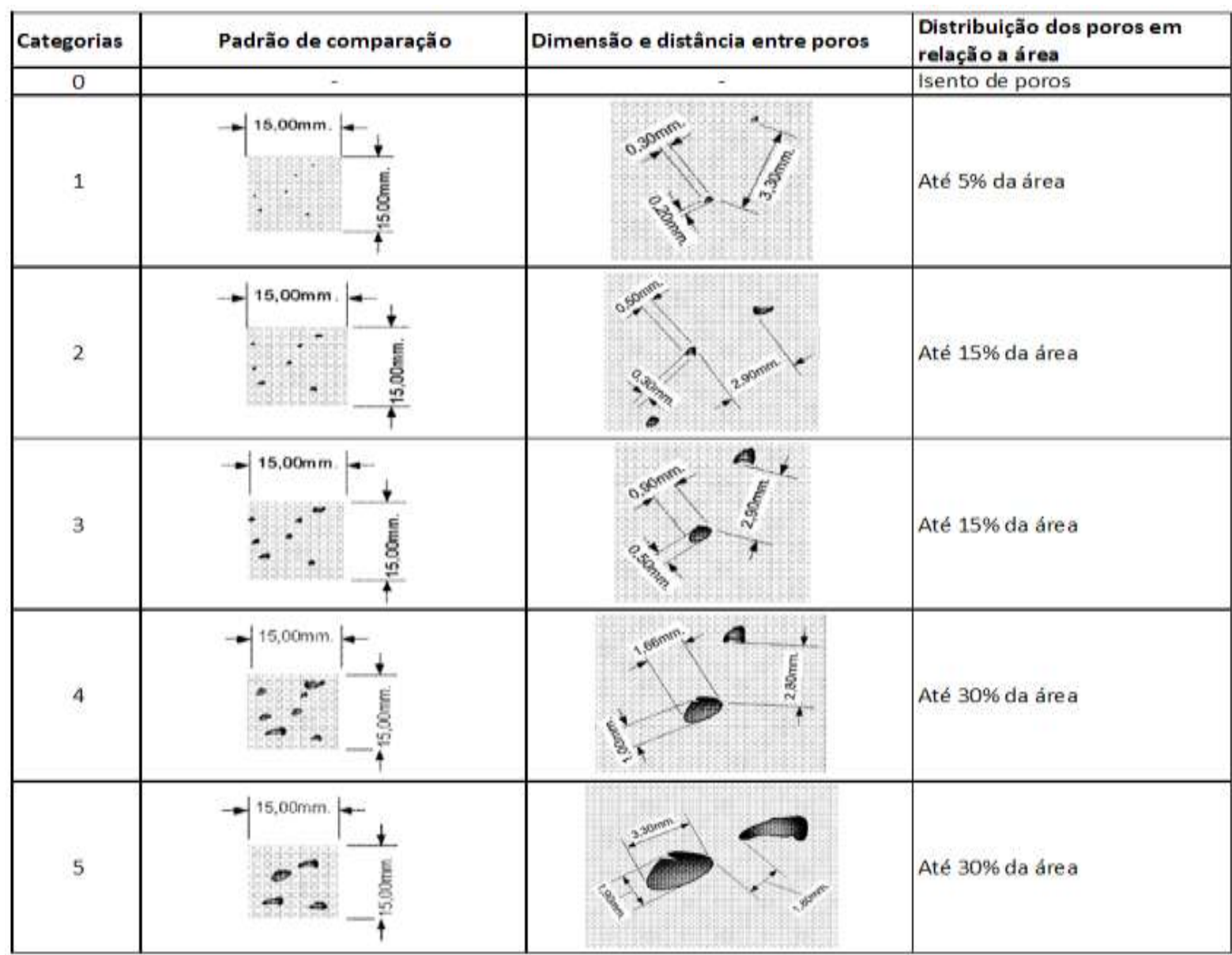

De acordo com o modelo de relação sinal-ruído ponderada apresentado no item 2.4.1 Relação Sinal-Ruído Ponderada, cada categoria de porosidade recebeu 
um peso proporcional à perda de qualidade gerada a partir da Função Perda de Qualidade. O coeficiente de custo $k$ foi calculado com o auxilio da Equação 4, a partir de um custo para a sociedade de 138,9 u.m., referente a custos típicos para a substituição do componente estudado quando o limite funcional, categoria 5 , é atingido. Sendo a porosidade uma característica de qualidade do tipo menor-émelhor, a Equação 2 foi utilizada para o cálculo das perdas para a sociedade em função de cada desvio da classe objetivo zero, ou seja, peças isentas de porosidade. Conforme o modelo de relação sinal-ruído ponderada, os pesos de cada classe são proporcionais a perda de qualidade, sendo adotados os valores dos pesos de cada categoria como sendo iguais aos valores das perdas.

Os pesos calculados para cada classe são apresentados na Tabela 4, e os cálculos do coeficiente k e da FPQ para a categoria 2 são ilustrados a seguir.

$$
\begin{aligned}
& k=\frac{A_{0}}{\Delta_{0}^{2}}=\frac{138,9}{5^{2}}=5,56 \\
& L\left(y_{2}\right)_{m \Theta M}=k y^{2}=5,56 \times 2^{2} \\
& L\left(y_{2}\right)_{m \Theta M}=22,2 \Rightarrow \omega_{2}=22,2
\end{aligned}
$$

Tabela 4 - Pesos de cada classe de porosidade

\begin{tabular}{ccccccc}
\hline & \multicolumn{7}{c}{ Categoria } \\
\cline { 2 - 7 } & 0 & 1 & 2 & 3 & 4 & 5 \\
\hline Peso & 0 & 5,6 & 22,2 & 50,0 & 88,9 & 138,9 \\
\hline
\end{tabular}

Os dados obtidos das classificações de todos os experimentos foram agrupados, e, por meio da Equação 5, foram calculadas as relações sinal-ruído ponderadas de cada rodada experimental.

\subsection{Análise e confirmação dos resultados}

A análise dos dados experimentais foi realizada por meio do efeito médio de cada nível dos fatores na relação sinal-ruído e da análise de variância. Sendo então determinados os níveis de fatores que resultam nas maiores relações sinal-ruído.

Para validar se a combinação de níveis de fatores selecionada realmente resulta na redução da porosidade das peças um experimento de confirmação foi realizado, sendo seguidas as mesmas considerações do experimento inicial. 


\section{RESULTADOS}

Após a realização de todos os experimentos foram feitas as classificações das porosidades encontradas nas áreas usinadas. Os dados de cada experimento são apresentados na Tabela 5, sendo agrupados de acordo com as categorias de poros nas áreas usinadas apresentadas anteriormente na Figura 7. Com base nos dados coletados, as relações sinal-ruído ponderadas de cada rodada de experimento foram calculadas a partir da Equação 5, sendo também apresentadas na Tabela 5. Como exemplo, o cálculo da RSRP do experimento 1 é apresentado a seguir:

$$
\eta_{1}=-10 \times \log \left[\frac{0^{2} .0+5,6^{2} .3+22,2^{2} \cdot 6+50^{2} .4+88,9^{2} \cdot 2+138,9^{2} \cdot 1}{16}\right]=-34,785 \mathrm{db}
$$

Tabela 5 - Dados experimentais agrupados por categoria de porosidade

\begin{tabular}{cccccccccc}
\hline \multirow{2}{*}{ Experimento № } & \multicolumn{7}{c}{ Frequência de observações por categoria } & & RSRP \\
\cline { 2 - 6 } \cline { 5 - 6 } & 0 & 1 & 2 & 3 & 4 & 5 & Total & $\eta$ \\
\hline 1 & 0 & 3 & 6 & 4 & 2 & 1 & 16 & $-34,785$ \\
2 & 0 & 3 & 4 & 7 & 1 & 1 & 16 & $-34,657$ \\
3 & 0 & 5 & 7 & 3 & 1 & 0 & 16 & $-30,749$ \\
4 & 0 & 2 & 6 & 7 & 1 & 0 & 16 & $-32,496$ \\
5 & 0 & 5 & 5 & 2 & 3 & 1 & 16 & $-35,002$ \\
6 & 0 & 0 & 4 & 8 & 2 & 2 & 16 & $-36,787$ \\
7 & 0 & 4 & 6 & 5 & 1 & 0 & 16 & $-31,667$ \\
8 & 0 & 4 & 3 & 2 & 5 & 2 & 16 & $-37,237$ \\
\hline Total & 0 & 26 & 41 & 38 & 16 & 7 & 128 & $-273,381$ \\
\hline
\end{tabular}

Utilizando os dados da Tabela 5, os efeitos médios de cada nível de fator na relação sinal-ruído foram calculados, sendo apresentados na Tabela 6. Conforme foi abordado na revisão da literatura, a melhoria da qualidade do produto é alcançada com a máxima relação sinal-ruído. Desta forma, na Tabela 6 são evidenciados os níveis de cada fator que possuem a maior relação sinal-ruído, e, portanto, é a melhor combinação de fatores. Sendo estes os fatores $A 1$, fator $A$ no nível 1, a temperatura do metal a $680^{\circ} \mathrm{C}, \mathrm{B} 2$ a velocidade da segunda fase de injeção a $4,2 \mathrm{~m} / \mathrm{s}$, C1 a velocidade da primeira fase de injeção a $0,2 \mathrm{~m} / \mathrm{s}$, D2 a pressão especifica da $3^{\mathrm{a}}$ fase a 1000 bar, E2 o curso da primeira fase de injeção à 270mm e F1 a temperatura do molde a $180^{\circ} \mathrm{C}$. O cálculo do efeito médio dos níveis dos fatores é feito com base na 
combinação dos níveis de fatores utilizados em cada experimento, conforme foi apresentado na Tabela 3. Como exemplo, a seguir é mostrado o cálculo do efeito médio dos níveis do fator $B$, que foi ajustado no nível 1 nos experimentos $1,2,5$ e 6 , e no nível 2 nos experimentos 3, 4, 7 e 8 .

$$
\begin{aligned}
& \overline{B_{1}}=\frac{-34,785-34,657-35,002-36,787}{4}=-35,308 d b \\
& \overline{B_{2}}=\frac{-30,749-32,496-31,667-37,237}{4}=-30,037 d b
\end{aligned}
$$

Tabela 6 - Efeito médio da Relação Sinal-Ruído Ponderado por fator

\begin{tabular}{ccccccc}
\hline \multirow{2}{*}{ Nivel } & \multicolumn{6}{c}{ Fator } \\
\cline { 2 - 7 } & A & B & C & D & E & F \\
\hline 1 & $-33,172$ & $-35,308$ & $-33,051$ & $-34,890$ & $-34,880$ & $-33,934$ \\
2 & $-35,173$ & $-33,037$ & $-35,294$ & $-33,456$ & $-33,465$ & $-34,411$ \\
\hline Melhor Combinação & A1 & B2 & C1 & D2 & E2 & F1 \\
\hline
\end{tabular}

A Figura 8 apresenta o gráfico do efeito médio da relação sinal-ruído de cada nível de fator, ilustrando como cada fator influenciou a resposta. No gráfico é possível observar que os fatores $A, B$ e C apresentaram maior variação entre a relação sinal-ruído de cada nível. Por outro lado, o fator $F$ não apresentou grande variação entre o nível 1 e 2.

Figura 8 - Influência dos níveis de fatores na relação sinal-ruído

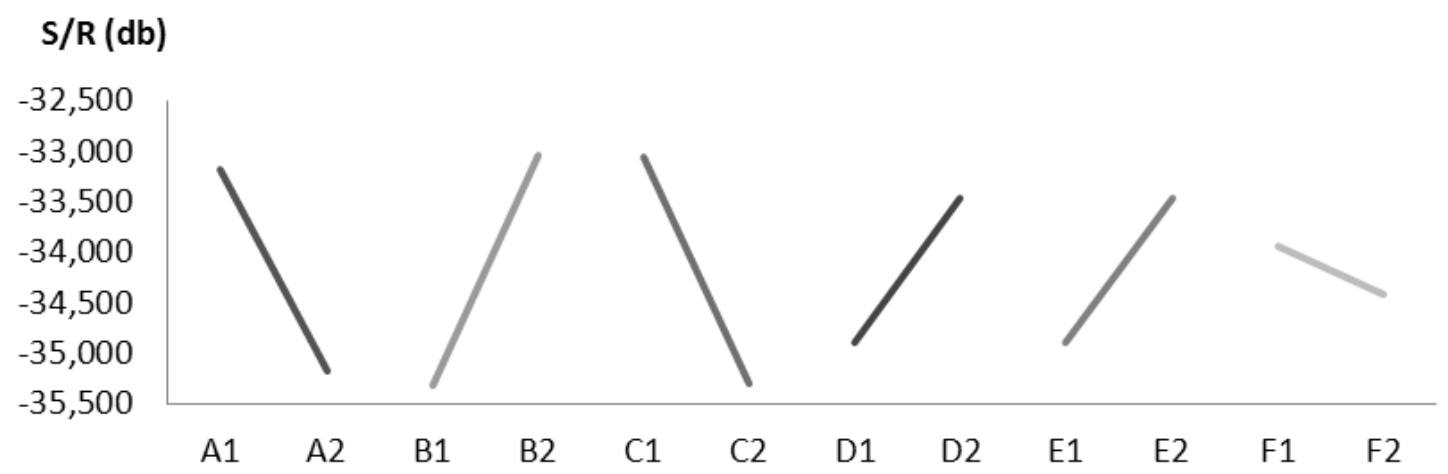

A análise de variância foi realizada utilizando-se os dados de relação sinalruído apresentadas na Tabela 5 , e seus resultados são apresentados na Tabela 7. As variâncias (coluna $V$ ) e as porcentagens de contribuição (coluna $P$ ) dos fatores $A$, 
$B$ e $C$ indicam que a temperatura do metal e velocidades da segunda e primeira fases de injeção são significantes. $\mathrm{E}$ ainda, as taxas de variância $(F)$ dos fatores $\mathrm{A}, \mathrm{B}$ e $C$ indicam, com um nível de confiança de $90 \%$ ( $\alpha=10 \%, F c=8,53)$, que eles exercem influência sobre a média, e por isso são relevantes. Por outro lado, não é possível afirmar com o mesmo nível de confiança que os níveis dos fatores $D$, E e $F$ estudados realmente influenciaram na média e são relevantes. Como exemplo, os cálculos da análise de variância do fator $D$ são apresentados a seguir.

$$
\begin{aligned}
& f_{D}=2-1=1 \\
& S Q_{D}=\frac{-139,558^{2}}{4}+\frac{-133,822^{2}}{4}-\frac{-273,381^{2}}{8}=4,11 \\
& V=\frac{4,11}{1}=4,11 \\
& S Q^{\prime}{ }_{D}=4,11-0,91 \times 1=3,20 \\
& P=\frac{3,20}{38,33} \times 100=8,34 \% \\
& F=\frac{4,11}{0,91}=4,50
\end{aligned}
$$

Tabela 7 - Análise de Variância (ANOVA)

\begin{tabular}{cccccc}
\hline Fator & $\boldsymbol{f}$ & SQ & $\boldsymbol{V}$ & $\boldsymbol{P}$ & $\boldsymbol{F}$ \\
\hline A & 1 & 8,01 & 8,01 & $18,52 \%$ & 8,77 \\
B & 1 & 10,31 & 10,31 & $24,51 \%$ & 11,28 \\
C & 1 & 10,07 & 10,07 & $23,88 \%$ & 11,02 \\
D & 1 & 4,11 & 4,11 & $8,34 \%$ & 4,50 \\
E & 1 & 4,00 & 4,00 & $8,06 \%$ & 4,38 \\
F & $(1)$ & $(0,46)$ & $(0,46)$ & Agrupado ao erro \\
Erro (e) & 2 & 1,83 & 0,91 & $16,69 \%$ & \\
\hline Total & 7 & 38,33 & \multicolumn{3}{c}{$100,00 \%$} \\
\hline
\end{tabular}

De acordo com os resultados apresentados na Tabela 7, pode-se observar que nas peças analisadas nos experimentos iniciais, a porosidade mais presente nas regiões usinadas era consequência principalmente do aprisionamento de gases, já que a pressão especifica da $3^{a}$ fase de injeção, responsável principalmente pela compensação da contração de solidificação, não apresentou grande relevância no comportamento da porosidade. Os parâmetros mais relevantes de acordo com a ANOVA corroboram com esta afirmação, pois a temperatura do metal e a velocidade 
da $2^{\mathrm{a}}$ fase de injeção estão diretamente relacionadas à turbulência do metal durante o preenchimento do molde, e a velocidade da $1^{a}$ fase de injeção ao aprisionamento de gases da câmara de injeção, sendo todos estes fatores críticos no aparecimento de porosidade por gases, conforme foi abordado na revisão da literatura.

\subsection{Experimento de confirmação}

Neste estudo o experimento de confirmação foi realizado com a combinação de parâmetros A1, B2, C1, D2, E2 e F1, conforme foi mostrado na Tabela 6 . Os demais procedimentos adotados nos experimentos anteriores tão foram adotados no experimento de confirmação. Os dados agrupados nas respectivas categorias e a as relações sinal-ruído encontradas podem ser vistos na Tabela 8. A distribuição das porosidades encontradas nas peças do experimento de confirmação mostra que ocorreu uma melhoria de qualidade em relação aos experimentos iniciais. Um aumento significativo na relação sinal-ruído ponderada também pode ser observado, sendo mais uma evidencia da melhoria de qualidade, conforme visto na revisão da literatura.

Tabela 8 - Dados do experimento de confirmação

\begin{tabular}{ccccccccc}
\hline \multirow{2}{*}{ Experimento № } & \multicolumn{9}{c}{ Número de observações por categoria } & & RSRP \\
\cline { 2 - 8 } & 0 & 1 & 2 & 3 & 4 & 5 & $\eta$ \\
\hline Confirmação & 5 & 6 & 4 & 1 & 0 & 0 & $-24,643$ \\
\hline
\end{tabular}

Os resultados encontrados mostram uma grande redução de porosidade presente nas peças em relação às configurações do experimento inicial. Os níveis ótimos de parâmetros responsáveis pela redução da porosidade são apresentados na Tabela 9.

Tabela 9 - Níveis ótimos de parâmetros.

\begin{tabular}{|c|c|c|c|}
\hline Descrição das Variáveis & Fator & Nivel & Valor \\
\hline Temperatura do metal $\left({ }^{\circ} \mathrm{C}\right)$ & A & 1 & 680 \\
\hline Velocidade da 2 a Fase de injeção $(\mathrm{m} / \mathrm{s})$ & B & 2 & 4,2 \\
\hline Velocidade da 1a Fase de injeção (m/s) & $\mathrm{C}$ & 1 & 0,2 \\
\hline Pressão Especifica da 3ạ Fase de injeção (BAR) & $\mathrm{D}$ & 2 & 1000 \\
\hline Curso da 1a Fase de injeção (mm) & $E$ & 2 & 270 \\
\hline Temperatura do molde $\left({ }^{\circ} \mathrm{C}\right)$ & $\mathrm{F}$ & 1 & 180 \\
\hline
\end{tabular}

Revista Produção Online, Florianópolis, SC, v.13, n. 4, p. 1435-1465, out./dez. 2013. 


\section{CONCLUSÕES}

O presente trabalho teve como objetivo a melhoria da qualidade de uma peça de alumínio fundida sob pressão, por meio da redução da porosidade. Para tal fim utilizou-se a aplicação do planejamento de experimentos, com bases nos métodos propostos por Taguchi, para estudar a influencia dos parâmetros do processo de fundição na porosidade resultante nas peças.

A configuração de fatores $A 1$, fator $A$ no nível 1, temperatura do metal em $680^{\circ} \mathrm{C}, \mathrm{B} 2$, velocidade da segunda fase de injeção em $4,2 \mathrm{~m} / \mathrm{s}, \mathrm{C} 1$, velocidade da primeira fase de injeção em $0,2 \mathrm{~m} / \mathrm{s}$, D2, pressão específica da $3^{\mathrm{a}}$ fase em 1000 bar, E2, curso da primeira fase de injeção em $270 \mathrm{~mm}$ e F1, temperatura do molde a $180^{\circ} \mathrm{C}$ resultou em peças classificadas com menos porosidades. Os fatores temperatura do metal, velocidade de primeira fase de injeção e velocidade de segunda fase de injeção foram os que apresentaram maior variação no efeito médio da relação sinal-ruído.

Por meio da análise de variância pode-se afirmar que os fatores que mais influenciaram na redução da porosidade da peça estudada foram a velocidade da segunda fase de injeção, velocidade de primeira fase de injeção e a temperatura do metal. E ainda, estes fatores apresentaram relevância, dentro de um nível de confiança de $90 \%$. Por outro lado, não é possível afirmar com o mesmo grau de confiança que os fatores pressão específica da terceira fase de injeção, curso da primeira fase de injeção e temperatura do molde influenciaram na redução da porosidade.

De acordo com os resultados obtidos, pode-se concluir que na peça estudada a porosidade mais presente nas regiões usinadas era gerada principalmente por aprisionamento de gases, já que a pressão especifica da $3^{a}$ fase de injeção não apresentou grande relevância no comportamento da porosidade. Os parâmetros mais relevantes reforçam esta conclusão, pois a temperatura do metal e a velocidade da $2^{\mathrm{a}}$ fase de injeção estão diretamente ligadas à turbulência do metal durante o preenchimento do molde, e a velocidade da $1^{\text {a }}$ fase de injeção ao aprisionamento de gases da câmara de injeção, sendo todos estes fatores 
geradores de porosidade por gases conforme foi apresentado na revisão da literatura.

O método de Taguchi se mostrou eficiente em fornecer a metodologia necessária para encontrar a melhor configuração de parâmetros que minimiza a porosidade da peça estudada, alcançando o objetivo proposto neste trabalho.

\section{SUGESTÕES PARA TRABALHOS FUTUROS}

Embora se tenha obtido resultados significativos de redução de porosidade nas peças estudadas, no experimento de confirmação ainda foram encontradas peças que apresentavam porosidade. Desta forma, fica a oportunidade de trabalhos futuros abordando:

- O teste dos fatores mais significativos em mais níveis.

- A inclusão fatores do processo não considerados neste estudo.

- A influência dos fatores do projeto do molde e da peça na porosidade.

\section{REFERÊNCIAS}

ALUINFO. Aluinfo: Portal técnico comercial do mercado de fundição de aluminio, 2012. Disponível em: <http://www.aluinfo.com.br/novo/conheca-o-bloco-de-motor-bimetalico-da-bmw>. Acesso em: 24 maio 2012.

AMMAR, H. R.; SAMUEL, A. M.; SAMUEL, F. H. Porosity and the fatigue behavior of hypoeutectic and hypereutectic aluminum-silicon casting alloys. International Journal of Fatigue, p.1024-1035, 2008.

ANASTASIOU, K. S. Optimization of the aluminium die casting process based on the Taguchi method. Proceedings of the institution of mechanical engineers, part $B$ :

Journal of Engineering Manufacture, p. 216, 2002.

APELIAM, D.; MAKHLOUF, M. M. High integrity aluminum die casting. Wheeling: North American Die Casting Association, 2006.

BREVICK, J. Die casting porosity guidebook. Wheeling: North American Die Casting Association, 2009.

CHIPMAN, H.; HAMADA, M. Bayesian analysis of ordered categorical data from industrial experiments. University of Waterloo. Waterloo, Canada. 1993. 
DARGUSCH, M. S.; DOUR, G.; SCHAUER, N.; DINNIS, C. M.; SAVAGE, G. The influence of pressure during solidification of high pressure die casting aluminium telecommunications components. Journal of Material Processing Technology, p.37-43, 2006.

EALEY, L. A. Quality by design: Taguchi Methods \& US Industry. [S.I.]: ASI Press, 1994.

FAURA, F.; LÓPEZ, J.; HERNÁNDEZ, J. On the optimum plunger acceleration law in the slow shot phase of pressure die casting machines. International Journal of Machine Tool \& Manufacture, p.173-191, 2001.

GOPALSAMY, B. M.; MONDAL, B.; GHOSH, S. Taguchi method and ANOVA: an approach for process parameters optimization of hard machining while machining hardened steel. Journal of Scientific \& Industrial Research, v. 68, 2009.

GUJARATI, D. N. Econometria básica. 4. ed. ed. Rio de Janeiro: Elsevier, 2006.

KIRKMAN, S. Shinkage porosity: a guide correcting the problems. Wheeling: North American Die Casting Association, 2006.

MALAVAZI, J. Área de fundição: Ppesso de fundição sob pressão. Osasco: SENAI, 2005.

MEDEIROS, M. História da fundição. São Paulo: Salus, 2009.

MENDES, R. P. K. Avaliação da influência dos parâmetros do processo de fundição sob pressão sobre a qualidade de uma peça injetada em liga de alumínio. Dissertação (Mestrado em Ciencia e Engenharia de Materiais) - Centro de Ciências Tecnológicas, Universidade do Estado de Santa Catarina, Joinville, 2005.

MONTGOMERY, D. C. Design and analysis of experiments. 7th Edition. ed. [S.I.]: John Wiley and Sons, Inc, 2009.

MUHAMMED, O. S.; SALEH, H. R.; ALWAN, H. L. Using of taguchi method to optimize the casting of $\mathrm{Al}-\mathrm{Si} / \mathrm{Al} 2 \mathrm{O} 3$ Composites. Engineering and Technology Journal, p.1143-1150, 2009.

NETO, M. F. Taguchi e a melhoria da qualidade: uma releitura crítica. Florianópolis: Editora da UFSC, 1997.

OLIVEIRA, E. C. D. Funções especiais com aplicações. 1 ed. ed. São Paulo: Livraria da Física, 2005.

RIBEIRO, C. B. Projeto de experimentos em rodas ferroviárias fundidas em aço, com o uso da técnica de Taguchi. Dissertação (Mestrado em Engenharia Mecânica) - Faculdade de Engenharia, Universidade Estadual Paulista, Guaratinguetá, 2008. 
ROSS, P. J. Aplicação das técnicas Taguchi na engenharia da qualidade. São Paulo: Makron, McGraw-Hill, 1991.

ROY, R. K. A primer on the Taguchi method. 2nd Edition. New York: Van Nostrand Reinhold, 2010.

SAVAS, O.; KAYIKCI, R. Application of Taguchi's methods to investigate some factors affecting microporosity formation in A360 alluminium alloy casting. Material and Design, p. 2224-2228, 9 Agosto 2007.

SYRCOS, G. P. Die casting process optimization using Taguchi methods. Journal of Materials Processing Technology, 2003.

TAGUCHI, G. Introduction to quality engineering. Tokyo: Asian Productivity Organization, 1986.

TAGUCHI, G.; CLAUSING, D. Robust Quality. Harvard Business Review, p.65-75, 1990.

TIAN, C.; LAW, J.; VAN DER TOUW, J.; MURRAY, M.; YOA, J. Y.; GRAHAM, D.; St. JOHN, D. Effect of melt cleanliness on the formation of porosity defects in automotive aluminium high pressure die castings. Journal of Materials Processing

Technology, p. 82-93, 2002.

TSOUKALAS, V. D. Optimization of porosity formation in AISi9Cu3 pressure die casting using genetic algorithm analysis. Materials and Design, p. 2027-2033, 2008.

VELOSO, P. L. C. Modelos para dados categóricos com estrutura temporal. Dissertação (Mestre em Estatística) - Instituto de Matemática, Universidade Federal do Rio de Janeiro, Rio de Janeiro, 2009.

VERRAN, G. O.; MENDES, R. P. K.; VALENTINA, L. V. O. D. DOE applied to optimization of aluminium alloy die castings. Journal of Materials Processing Technology, p.120-125, 2008.

VIJIAN, P.; ARUNACHALAM, V. P. Optimzation of squeeze cast parameters of LM6 aluminium alloy for surface roughness using Taguchi method. Journal of Material Processing Technology, p.161-166, 30 Maio 2006

VINARCIK, E. J. High integrity die casting processes. New York: John Wiley \& Sons, 2003.

WALKINGTON, W. Gas porosity: a guide to correting the problems. Wheeling: North American Die Casting Association, 2006.

WANG, L.; TURNLEY, P.; SAVAGE, G. Gas content in high pressure die casting. Journal of Materials Processing Technology, p.1510-1515, 2011. 
WEN, J.-L.; YANG, Y.-K.; JENG, M.-C. Optimization of die casting conditions for wear properties of alloy AZ91D components using the Taguchi method and design of experiments analysis. International Journal of Advanced Manufacturing Technology, p. 430-439, 5 Junho 2009.

WU, D. H.; CHANG, M. S. Use of Taguchi method to develop a robust design for the magnesium alloy die castng process. Mateirals Science \& Engeneering A, 2004.

WU, F.-C.; YEH, C.-H. A comparative study on optimization methods for experiments with ordered categorical data. Computers \& Industrial Engeneering, p. 220-232, 2006.

YENIDUNYA, B. Robust design with binary response using Mahalanobis Taguchi System. Thesis (Master of Science in Industrial Engineering) - Middle East Technical University, [S.I.], 2009.

ZHAO, H. D.; WANG, F.; LI, Y. Y.; XIA, W. Experimental and numerical analysis os gas entrapment defects in plate ADC12 die casting. Journal of Materials Processing Technology, p. 4537-4542, 2009.

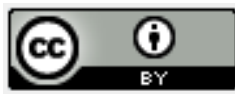

Artigo recebido em 31/08/2012 e aceito para publicação em 09/06/2013. 